TMD is all about muscles protecting teeth. It really isn't more complex than that. A typical example would be a patient who, if positioned properly in centric relation would only have posterior contact and an open bite. Functioning in this position would be comfortable, and this triggers the classic old brainstem-level avoidance reflex such that the muscles of mastication reposition the mandible (at the expense of condylar position) to avoid that trauma.

The challenge is that you can't identify these interferences very easily, because those powerful muscles will work very hard to protect the teeth when you try to manipulate that mandible. You have to deprogramme those muscles first, and that's where (properly adjusted) occlusal splints come in. Without deprogramming, you can't identify the interferences in the first place. I suspect that's where a lot of the 'research' problem lies. Occlusal splint therapy is an art and science in itself and not the easiest thing in the world to do - properly.

In the 1970s and 1980s, treatment was all about equilibration. In hindsight, it was foolish to do invasive treatment on an unstable patient. You need to stabilise them with an occlusal splint first, which is not easy and takes months along with skill and expertise to be effective. Given all these factors, the most refractory patient can stabilise even in the presence of degenerative joint disease. Other very important aspects to occlusion are spinal-cervical connections, restricted envelopes of function, and the critical need to restore anterior tooth length and nociceptive input to avoid lateralised function.

The best restorative and periodontal care will fail with a bad occlusion. If you understand occlusion, you will avoid many things that will get you into trouble in dentistry. And if you do get into trouble, understanding occlusion will generally get you out of it.

M. Antosz, Calgary, Canada DOI: 10.1038/sj.bdj.2018.452

\section{Education and CPD}

\section{Outstanding resources}

Sir, over this year's rather wet Easter holiday I caught up with some reading of the Journal and the section 'Other journals in brief' has really captured my eye. As a dental educator in an outreach primary care setting I found the reviews in Volume 224 No 5 by Paul
Hellyer ${ }^{1}$ particularly apposite, discussing school interventions of oral health education and fluoride varnish application. I will certainly be challenging my new cohort of students, who undertake such activity in outreach, ${ }^{2}$ to read these abstracts during their induction at the University of Portsmouth Dental Academy.

On the other hand the reviewed papers by Reena Wadia ${ }^{3}$ on diabetes and periodontal markers, I found useful as a personal update in this developing area. Both these topics I feel are of relevance and must be outstanding resources and of value to our colleagues who are vocational educational supervisors faced with another year of giving their trainees up-to-date and relevant tutorials as another 980 or so new dentists qualify into vocational training this summer. Naturally some of the papers chosen are published in journals that do not have a policy of open access publishing but over the recent months, I have found the librarian at the BDA library a very user friendly outstanding resource for accessing journals that have proven difficult to access even with my recourse to the resources of King's College London.

\section{R. Radford, Portsmouth}

1. Hellyer P. Research insights: Other journals in brief. Br Dent J 2018; 224: 357

2. Radford D R, Weld J A. Micro-educational opportunities in outreach clinical dental education. Br Dent J 2013; 215: 389-391.

3. Wadia R. Research insights: Other journals in brief. Br Dent J 2018; 224: 427

DOI: $10.1038 /$ sj.bdj.2018.453

\section{Ethics}

\section{The ethical dentist}

Being ethical in your approach as a dentist matters, correct? I am sure every dentist reading this would agree. I wanted to give my experience on the topic from the perspective of an 'expert member' on one of the Research Ethics Committees (RECs) for the West Midlands branch of the Health Research Authority (HRA).

I don't believe I am particularly more ethical than any other dentist out there, but I do believe I have additional insight into what it means to be ethical from a patient point of view and what factors should be considered. I wanted to share my experience of being a relatively new member of the ethics committee for the HRA, what it means and how it helps inform and develop my ethical practice.
I found out about RECs through a former colleague and fellow dentist. She invited me to come along to a meeting and see what it was all about. Being the inquisitive (and perhaps nosey!) person I am, I thought it would be something different, interesting and very relevant to my clinical practice. As a committee, we read health research study proposals that involve human participants and scrutinise the ethical issues associated with the studies. We are constantly looking from a patient/ participant's perspective and not from a researcher's perspective. As a clinician, I find this refreshing; it helps me to focus on putting the participant's best interests first, and supports a selfless, caring and ethical approach to healthcare.

The panel is made up of around eight members, but this can vary from week to week. Members are either 'expert' (from a healthcare/science background) or lay (any member of the public). We have research proposals sent to us in advance of the monthly meetings to read and annotate with any issues, comments or concerns we may find, and then at the meeting we discuss them prior to raising them with the visiting researcher/s. We then, on deliberation after the researcher has left, come to a decision regarding whether or not to approve the research to go ahead.

It is certainly a position of trust and a position of responsibility; something I developed through my early years as a qualified dentist. My voluntary work with the research ethics committee really compliments my day job! I have also improved my team working and leadership skills as a result, and my confidence as a relatively new clinician is also improving. I am keeping healthcare research integral to my educational development, and have undertaken committee member training for the role. At each meeting I am learning more about what it means to be an ethical decision maker.

It is not something I knew anything about prior to joining, but now I feel enriched, better informed and feel my patient care is going that one step further as a result.

If you are interested you can find out more at: https://www.hra.nhs.uk/about-us/ committees-and-services/res-and-recs/ become-rec-member/

C. Doswell, Birmingham DOI: 10.1038/sj.bdj.2018.454 